\title{
Marking wire technique for zero-contrast percutaneous coronary interventions
}

\author{
Jerzy Sacha \\ Department of Cardiology, University Hospital, University of Opole, Opole, Poland
}

Adv Interv Cardiol 2018; 14, 2 (52): 204-205

DOI: https://doi.org/10.5114/aic.2018.76416

Zero-contrast percutaneous coronary intervention $(\mathrm{PCl})$ is a new and promising approach in the prevention of contrast-induced nephropathy [1, 2]. It has been previously shown that by using this technique even $\mathrm{PCl}$ of the left main stem can be done [3]. However, one of its biggest challenges is the precise positioning of stents according to landing zones determined by intravascular ultrasound (IVUS). Performed in a case of right coronary artery stenosis (Figure $1 \mathrm{~A}$ ), a new technique is presented which significantly facilitates stent implantation without contrast administration.

In order to establish both distal and proximal landing zones as well as to determine the stent length, two guidewires should be inserted through a double $Y$ connector and a $7 \mathrm{Fr}$ guiding catheter. The operating wire is inserted via the main port of the connector but the marking wire via its side port (Figure $1 \mathrm{~B}$ ) - the marking wire is intended to guide the intervention. The distal landing zone is determined by IVUS and subsequently marked with the tip of the marking wire, i.e. by pulling back the wire to the level of the landing zone (Figure $1 \mathrm{C}$ ). Then, the position of the marking wire is secured by tightly screwing the connector's side port and additionally a torquer is attached to prevent any displacement of the wire (Figure 1 B). Subsequently, the proximal landing zone and the stent length are determined by IVUS (Figure $1 \mathrm{D}$ ). Finally, the stent is located accord- ing to the position of the marking wire (Figure $1 \mathrm{E}$ ) and after removal of the wire it can be implanted. In the presented case, after balloon post-dilation and IVUS examination, one single injection of $5 \mathrm{ml}$ of contrast was performed to document the $\mathrm{PCl}$ result and lack of complications (Figure $1 \mathrm{~F}$ ).

This simple technique may significantly facilitate stent implantation and reduce the stent length, which is usually longer in $\mathrm{PCl}$ without contrast.

\section{Conflict of interest}

The author declares no conflict of interest.

\section{References}

1. Ali ZA, Karimi Galougahi K, Nazif T, et al. Imaging- and physiology-guided percutaneous coronary intervention without contrast administration in advanced renal failure: a feasibility, safety, and outcome study. Eur Heart J 2016; 37: 3090-5.

2. Karimi Galougahi K, Mintz GS, Karmpaliotis D, Ali ZA. Zero-contrast percutaneous coronary intervention on calcified lesions facilitated by rotational atherectomy. Catheter Cardiovasc Interv 2017; 90: E85-9.

3. Sacha J, Feussette P. How should I treat unprotected LM stenosis in a patient with ACS who develops a severe contrast-induced nephropathy after coronary angiography? https://www. pcronline.com/Cases-resources-images/Cases/EIJ-HSIT/Treatment-strategy-for-left-main-stenosis-in-patient-with-CIN?auth=true\#comments_area (Published, 06 December 2017).

\section{Corresponding author:}

Jerzy Sacha MD, PhD, Department of Cardiology, University Hospital, University of Opole, Al. Witosa 26, 45-401 Opole, Poland, phone: +48 7745206 60, +48 600273 616, fax: +48 7745206 99, e-mail: sacha@op.pl

Received: 25.02.2018, accepted: 20.03.2018. 

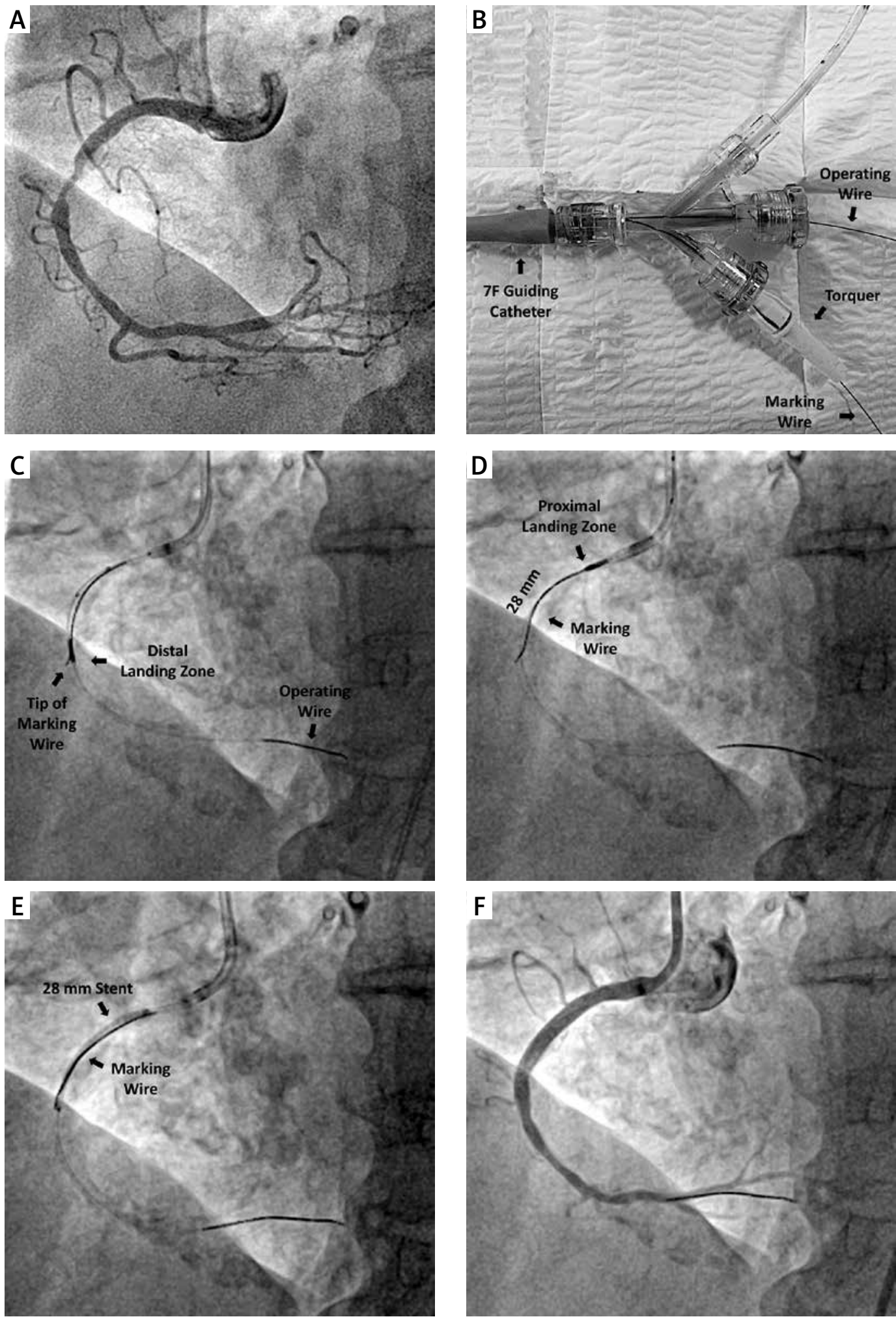

Figure 1. A - Right coronary artery angiography in a patient with significant renal impairment performed several days prior to $\mathrm{PCl}$. B - The double $\mathrm{Y}$ connector is attached to the $7 \mathrm{Fr}$ guiding catheter and two guidewires are inserted, i.e. the operating and marking ones - for stability of the whole system (particularly for stability of the marking wire), the size of the guiding catheter should not be smaller than 7 Fr. $\mathbf{C}$ - The distal landing zone is marked with the tip of the marking wire according to the position of the IVUS probe. D - The proximal landing zone is determined by the IVUS probe and the stent length may be measured with the help of marking wire. $\mathrm{E}$ - The stent is positioned according to the marking wire. $\mathrm{F}-$ Final result of $\mathrm{PCl}$ 